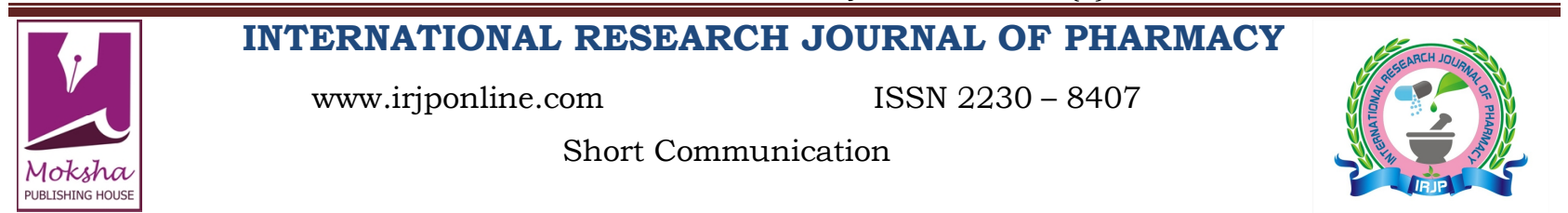

\section{QUANTITATIVE ESTIMATION OF GALLIC ACID IN ROSA SINENSIS, EMBLICA OFFICINALIS AND SYZYGIUM AROMATICUM BY HPTLC}

\author{
Mehrotra Shubhi ${ }^{1}$, Kirar Vandana ${ }^{2}$, Misra Kshipra ${ }^{2}$, Nandi Shoma Paul ${ }^{1 *}$ \\ ${ }^{1}$ Amity Institute of Biotechnology, Amity University, Noida, India \\ ${ }^{2}$ Defence Institute of Physiology and Allied Sciences (DIPAS), Delhi, India \\ *Corresponding Author Email: shoma.amity@gmail.com
}

Article Received on: 13/05/13 Revised on: 07/06/13 Approved for publication: 21/07/13

DOI: 10.7897/2230-8407.04719

IRJP is an official publication of Moksha Publishing House. Website: www.mokshaph.com

(c) All rights reserved.

\section{ABSTRACT}

A number of plants are rich source of gallic acid, a pharmacologically important molecule which exists either in free form or as a part of the tannin molecule. The present study was designed to identify and compare the presence of gallic acid in the ethanolic extracts of three Indian medicinal plants, Emblica officinalis, Syzygium aromaticum and Rosa sinensis by high performance thin layer chromatography. The pulp of Emblica officinalis had the highest content of gallic acid, $27.36 \mathrm{mg} / \mathrm{g}$ of dry weight of extract. The gallic acid content in the petals and buds of Rosa sinensis and Syzygium aromaticum was $12.76 \mathrm{mg} / \mathrm{g}$ and $25.98 \mathrm{mg} / \mathrm{g}$ of dry weight respectively. The $\mathrm{R}_{\mathrm{f}}$ value of gallic acid was found to be 0.29 . This study significantly compares the presence of gallic acid in the three extracts which are a potential source of antioxidant activity.

Keywords: Gallic acid, HPTLC, Rosa sinensis, Syzygium aromaticum, Emblica officinalis.

\section{INTRODUCTION}

High performance thin layer chromatography (HPTLC) can be used qualitatively and quantitatively for the estimation of chemical constituents present in the plant materials ${ }^{1}$. Gallic acid is found in tea, red wine, fruits and beverages and in various other medicinal plants ${ }^{2}$. Chemically it is 3, 4, 5trihydroxybenzoic acid. It possess astringent activity, antiinflammatory, cardio-protective, antioxidant activity and are proven to show beneficial effects on human health ${ }^{3}$. They also have anti-carcinogenic, anti-hepatotoxic, antiischaemic, anti-allergic, anti-ulcerative activities ${ }^{4}$. All these properties make gallic acid a very important molecule with medicinal value, therefore the study was undertaken to identify and compare the presence of gallic acid in ethanolic extracts of three Indian medicinal plants, Emblica officinalis, Syzygium aromaticum and Rosa sinensis by HPTLC.

\section{MATERIALS AND METHODS}

\section{Collection and Identification of the Plants}

Petals of Rosa sinensis were collected from Amity Institute of Organic Agriculture Farm, Noida, India. The fruits of Emblica officinalis were collected from Bharmar village, Himachal Pradesh, India and the buds of Syzygium aromaticum were purchased from a local market, Noida, India. All the plant materials were identified by Z.Y. Rizvi, Senior horticulturist, Government of India.

\section{Preparation of the Plant Extracts}

Ethanolic extracts of the plants were prepared as per the extraction procedure mentioned earlier by Mehrotra et al. ${ }^{5}$.

\section{Standard and Reagents}

Standard gallic acid was obtained from Sigma-Aldrich Chemie (Steinheim, Germany). Analytical grade chloroform, ethyl acetate and formic acid used as solvent system were obtained from Qualigens Fine Chemicals, India.

\section{Preparation of Standard Solution of Gallic Acid}

For preparation of standard curve $0.5 \mathrm{mg} / \mathrm{ml}$ solution of standard gallic acid was prepared by dissolving gallic acid in $100 \%$ methanol.

\section{High Performance Thin Layer Chromatography}

Three levels $(0.3 \mu \mathrm{g}, 0.4 \mu \mathrm{g}$ and $0.5 \mu \mathrm{g})$ of standard gallic acid were used for the calibration curve for which $0.6 \mu \mathrm{l}$, $0.8 \mu \mathrm{l}$ and $1.0 \mu \mathrm{l}$ of standard solution was applied in duplicate as bands of $5 \mathrm{~mm}$ using a Camag microlitre syringe on a precoated silica gel plate $60 \mathrm{~F}_{254}[10 \mathrm{~cm} X 10$ $\mathrm{cm}$ with $0.2 \mathrm{~mm}$ thickness, E. Merck] using a semi automatic Linomat V sample applicator. The plates were developed in a solvent system in CAMAG glass twin through chamber $[20 \mathrm{~cm}$ X $10 \mathrm{~cm}$ ] previously saturated with the solvent (chloroform: ethyl acetate: formic acid= 7.5: 6: 0.5 ) for 30 minutes. (Figure 1). The TLC plates were air dried and scanning was performed on a Camag TLC Scanner III at $254 \mathrm{~nm}$ using Wincats software 4.03 version 1 (Figure 2 and 3). The mean peak height / area of duplicate samples was calculated and the content of gallic acid was quantified using the regression equation obtained from the standard curve ${ }^{6}$.

\section{RESULT AND DISCUSSION}

The standard gallic acid has $\mathrm{R}_{\mathrm{f}}$ value of 0.29 [Figure 2(A)]. A good linear relationship $\left(r^{2}=0.99612\right.$ and 0.99771 with respect to peak area and height, respectively) was observed between the concentration ranges of $0.05 \mu \mathrm{g}$ to $0.5 \mu \mathrm{g}$. The regression equation was found to be $\mathrm{Y}=6.764+0.3748^{*} \mathrm{X}$ with respect to height and $\mathrm{Y}=176.3+10.46^{*} \mathrm{X}$ with respect to area, where $\mathrm{Y}$ is the peak height / area and $\mathrm{X}$ is the concentration of standard gallic acid. Out of the three ethanolic extracts (Rosa sinensis petals, Emblica officinalis pulp and Syzygium aromaticum buds), the pulp of Emblica officinalis had the highest content of gallic acid, $27.36 \mathrm{mg} /$ $\mathrm{g}$ of dry weight of extract [Figure 2(C)] and similar observation was also reported by Borde et al. ${ }^{2}$ 


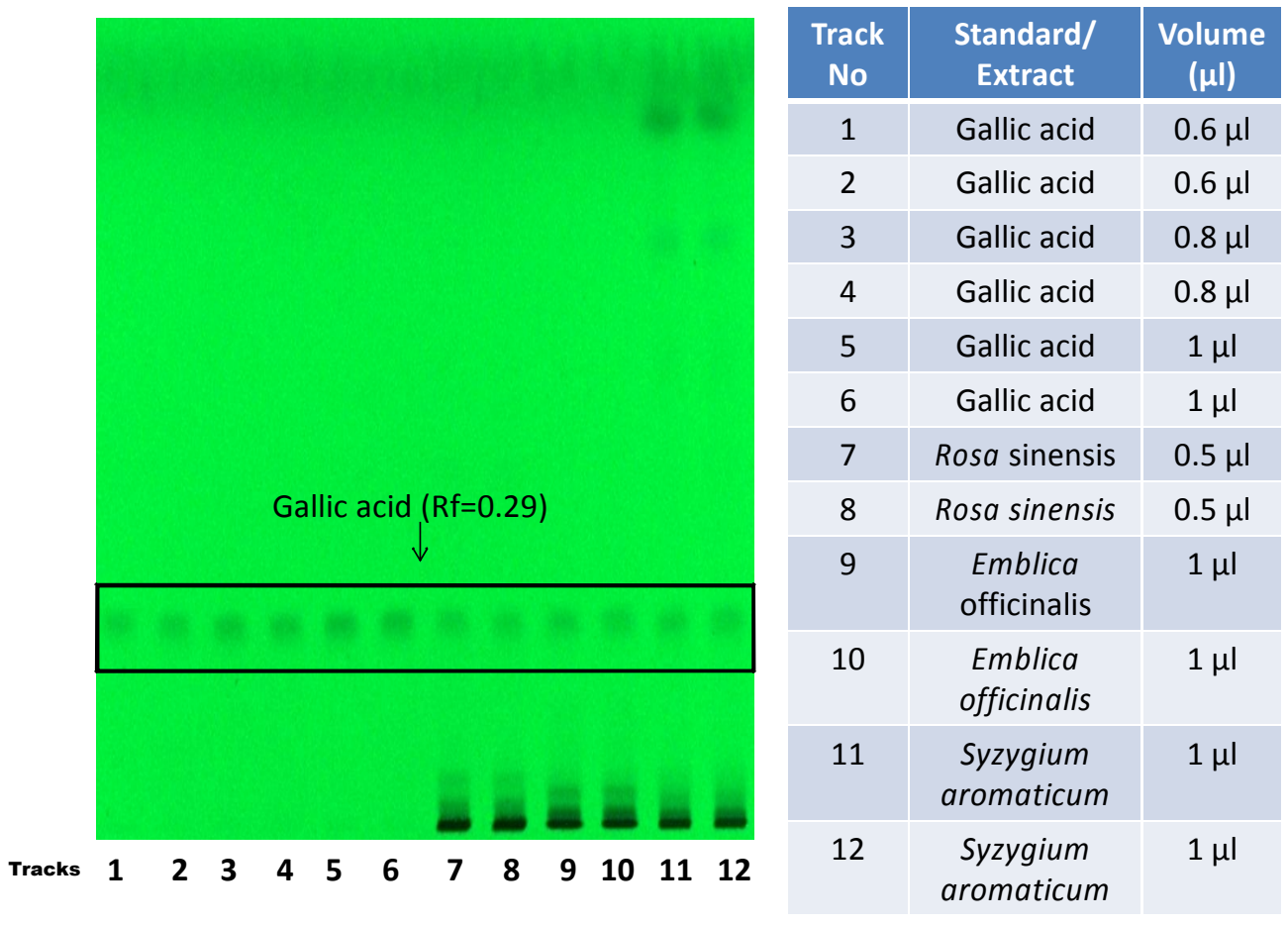

Figure 1: HPTLC chromatogram of gallic acid, Rosa sinensis (petal), Emblica officinalis (pulp) and Syzygium aromaticum (bud) extracts at $254 \mathrm{~nm}$ using Chloroform: Ethyl acetate: Formic acid $=7.5: 6: 0.5$ as solvent system. The details of the individual tracks are listed as tabular form in the right
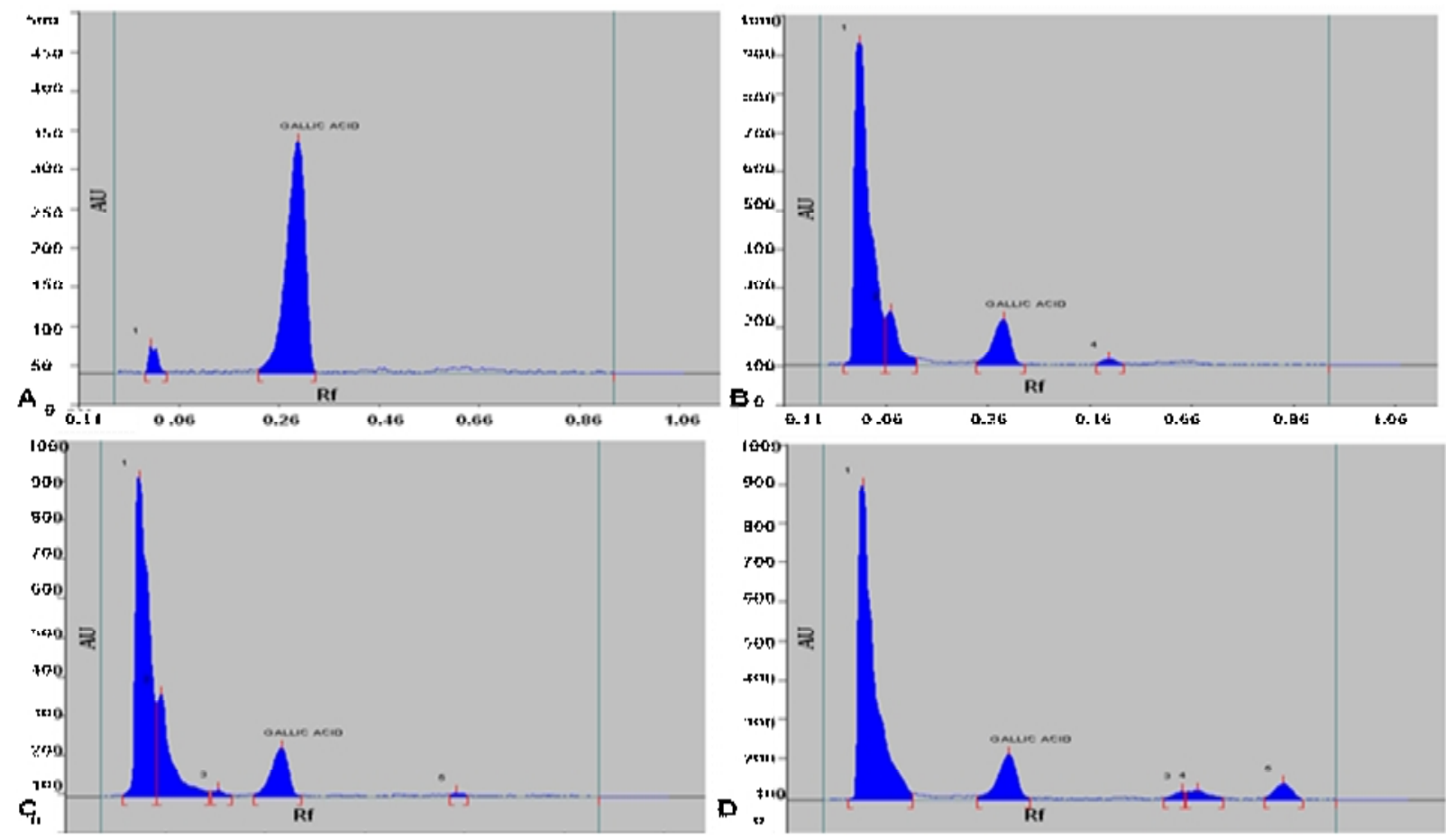

Figure 2: HPTLC chromatograms of A. standard gallic acid $\left(R_{\mathrm{f}}=0.29\right)$; B. ethanolic extract of Rosa sinensis (petal); C. ethanolic extract of Emblica officinalis (pulp); D. ethanolic extract of Syzygium aromaticum (bud); mobile phase: chloroform:ethyl acetate: formic acid (7.5: 6: 0.5), $X$ axis corresponds to $R_{f}$ and $Y$ axis corresponds to absorbance 


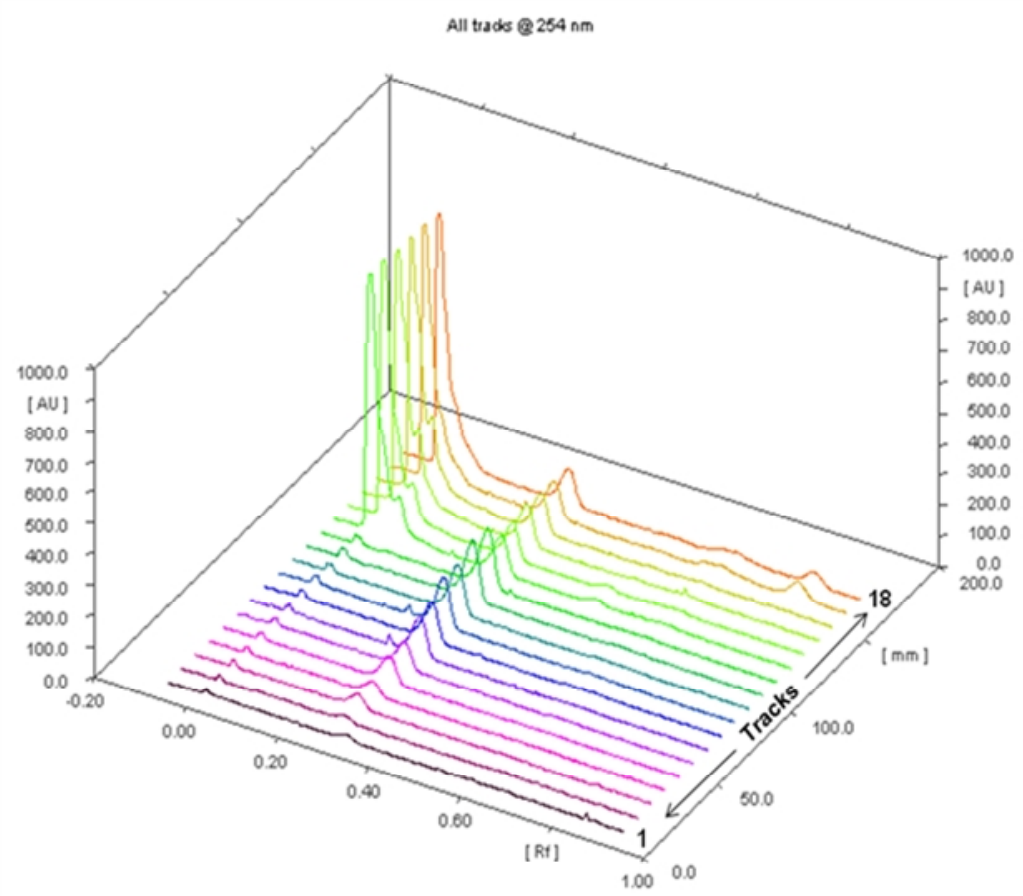

Figure 3: HPTLC three-dimensional image of the calibration curve of gallic acid (tracks 1to 12; $0.1 \mu \mathrm{l}$ - $1 \mu \mathrm{l}$ ) from Rosa sinensis petal (tracks 13 and 14; $0.5 \mu \mathrm{l}$ ), Emblica officinalis pulp (tracks 15 and 16; $1 \mu \mathrm{l}$ ) and Syzygium aromaticum bud (tracks 17 and $18 ; 1 \mu \mathrm{l}$ ) extracts at $254 \mathrm{~nm}$. $X$ axis corresponds to $R_{f}$ and $Y$ axis corresponds to absorbance

The gallic acid content in the petals of Rosa sinensis was $12.76 \mathrm{mg} / \mathrm{g}$ of dry weight of extract [Figure 2(B)] and in the buds of Syzygium aromaticum was $25.98 \mathrm{mg} / \mathrm{g}$ of dry weight of extract [Figure 2(D)]. The UV spectrum of the plant extracts was super-imposable (Figure 3) with that of the standard gallic acid indicating the purity of the peak and the presence of the standard (gallic acid) tested (Figure 3). Simplicity, specificity and sensitivity of the developed HPTLC method makes it a suitable method for monitoring the gallic acid content for standardization of raw materials at the time of formulating a preparation using the crude extract as well as for the quality control of the finished product.

\section{CONCLUSION}

The standard gallic acid was quantitatively determined in ethanolic extracts of three different plants. Emblica officinalis (pulp) contains the highest gallic acid content, followed by Rosa sinensis (petal) and then by Syzygium aromaticum (bud). The $\mathrm{R}_{\mathrm{f}}$ value of gallic acid was found to be 0.29 . This study is important as it quantitatively compares the presence of gallic acid in three extracts which is a potential source of antioxidant activity by a very simple and reliable-HPTLC.

\section{ACKNOWLEDGEMENT}

Financial assistance was received from Department of Biotechnology, Ministry of Science and Technology (BT/40/NE/TBP/2010).

\section{REFERENCES}

1. Ravishankara MN, Shrivastava N, Jayathirtha MG, Padh H, Rajani M. A sensitive High-performance thin layer chromatographic method for the estimation of diospyrin, a tumour inhibitory agent from the stem bark of Diospyros montana Roxb. J. Chromatography B 2000; 744: 257-262. http://dx.doi.org/10.1016/S0378-4347(00)00277-2

2. Borde VU, Pangrikar PP, Tekale SU. Gallic acid in Ayurvedic herbs and formulations. Recent Res Sci Tech 2011; 3: 51-54.

3. Sajeeth CI, Manna PK, Manavalan R, Jolly CI. Quantitative estimation of gallic acid, rutin and quercetin in certain herbal plants by hptlc method. Der Chemica Sinica 2010; 1(2): 80-85.

4. Shahidi F, Naczk M. Phenolics in food and nutraceuticals.USA: CRC Press LLC; 2004.

5. Mehrotra S, Srivastava AK, Nandi SP. Comparative antimicrobial activities of Neem, Amla, Aloe, Assam tea and Clove extracts against Vibrio cholerae, Staphylococcus aureus and Pseudomonas aeruginosa. J. Medicinal Plants Res 2010; 4(22): 2393-2398.

6. Rakesh SU, Salunkhe VR, Dhabale PN, Zburade KB. HPTLC method for quantitative determination of gallic acid in hydroalcoholic extract of dried flowers of Nymphaea stellata Willd. Asian J. Res Chem 2009; 2(2): 131-134.

Cite this article as:

Mehrotra Shubhi, Kirar Vandana, Misra Kshipra, Nandi Shoma Paul. Quantitative estimation of gallic acid in Rosa sinensis, Emblica officinalis and Syzygium aromaticum by HPTLC. Int. Res. J. Pharm. 2013; 4(7):87-89 http://dx.doi.org/10.7897/2230-8407.04719 